\title{
HVDC Circuit Breakers A Review Identifying Future Research Needs
}

\section{Journal Article}

\section{Author(s):}

Franck, Christian (i)

Publication date:

2011-04

Permanent link:

https://doi.org/10.3929/ethz-b-000034312

Rights / license:

In Copyright - Non-Commercial Use Permitted

Originally published in:

IEEE Transactions on Power Delivery 26(2), https://doi.org/10.1109/TPWRD.2010.2095889 


\section{2011 IEEE.}

Personal use of this material is permitted. Permission from IEEE must be obtained for all other uses, in any current or future media, including reprinting/republishing this material for advertising or promotional purposes, creating new collective works, for resale or redistribution to servers or lists, or reuse of any copyrighted component of this work in other works."

Digital Object Identifier: 10.1109/TPWRD.2010.2095889 


\title{
HVDC Circuit Breakers: A Review Identifying Future Research Needs
}

\author{
Christian M. Franck, Member, IEEE
}

\begin{abstract}
The continuously increasing demand for electric power and the economic access to remote renewable energy sources like off-shore wind power or solar thermal generation in deserts have revived the interest in high-voltage direct current (HVDC) multi-terminal systems (networks). A lot of work was done in this area, especially in the 1980's, but only two threeterminal systems were realized. Since then, HVDC technology has advanced considerably and, despite numerous technical challenges, the realization of large-scale HVDC networks is now seriously discussed and considered. For the acceptance and reliability of such networks, the availability of HVDC circuit breakers will be critical, making them one of the key enabling technologies. Numerous ideas for HVDC breaker schemes have been published and patented, but no acceptable solution has been found to interrupt HVDC short-circuit currents. This article aims to summarize the literature, especially that of the last two decades, on technology areas that are relevant for HVDC breakers. By comparing the, mainly $20+$ years old, state-of-the art HVDC circuit breakers to the new HVDC technology, existing discrepancies become evident. Areas where additional research and development is needed are identified and proposed.
\end{abstract}

Index Terms-HVDC circuit breakers, HVDC interrupters, HVDC transmission, HVDC converters, Switchgear, Power transmission.

\section{INTRODUCTION}

$\mathbf{I}$ $\mathrm{N}$ recent years the interest in HVDC multi-terminal systems has been revived. The continuously increasing demand for electric power and the economic access to remote renewable energy sources like off-shore wind power [1]-[3] or solar thermal generation in deserts [4] require an electric energy transmission system that bridges very long distances with low losses. Traditional HVDC point-to-point systems can help to serve this duty and are available today. Linking more than two HVDC terminals to form a meshed multi-terminal HVDC system (network) would have several advantages: the reduction in number of terminals (reduced costs and losses), the outage of one DC line does not interrupt the power flow at any terminal, each terminal can be operated at a different power and current, and the power exchange with all $\mathrm{AC}$ connection points can be fully controlled. It is thus very attractive to explore the realization of HVDC networks. There was considerable interest in multi-terminal HVDC systems in the 1980 's, but only two three-terminal systems were realized [5], [6]. The advances in HVDC technology also helped to renew the interest in HVDC networks. In particular, voltage source converter (VSC) HVDC is now available. However, the acceptance of HVDC networks with respect to efficiency,

Christian M. Franck is with the Institute for Power Systems and High Voltage Technology, ETH Zurich, 8092 Zurich, Switzerland, cfranck@ethz.ch Manuscript submitted April 12, 2010. reliability and controllability will be strongly dependent on the availability of HVDC circuit breakers, making them one of the key enabling technology [7]-[10].

There are significant differences between the requirements of $\mathrm{AC}$ and DC circuit breakers, mainly due to the absence of a natural current zero crossing in DC systems. DC breakers have to interrupt short-circuit currents very quickly and need to dissipate the large amount of energy which is stored in the inductances in the system. Today, DC circuit breakers are only widely available for the low and medium voltage range. For HVDC applications, only transfer and load current switches are in use. Breakers interrupting HVDC short-circuit currents are not commonly available and have very limited ratings. Numerous proposals for breaker designs have been presented in articles and patent applications. All comprise different series and parallel connections of classical AC interrupters, resonance circuits with inductors and capacitors, semiconductors, charging units, varistors, or resistors. Each of the numerous concepts has certain advantages and drawbacks. Most of the publications address only a few, or even only a single, aspect of the many requirements, but no contribution has tried to give an overall picture.

This paper is structured as follows: Chapter II reviews the basics of HVDC technology and the possibility of building networks with it. Special emphasize is put on the differences between the classical current source converter (CSC) and the more recent VSC technology and the consequences for HVDC networks. Chapter III reviews the literature on HVDC circuit breakers with focus on the most recent developments. There are differences in the demands on circuit breakers in CSC and VSC HVDC networks. These different demands are compared with HVDC circuit breaker schemes and recent advances in related technological areas. By this, research needs are identified throughout the text and summarized in chapter IV, which concludes the papers.

The main aim of this paper is to give an overview of HVDC circuit breakers, to identify areas where research and development are needed and, by this, to revive the discussion on this subject. Obviously, the paper cannot discuss each of these identified needs in detail. But, by citing relevant literature, it should serve as a reference point for others working in this area.

\section{HVDC NETWORKS}

HVDC systems have two main uses: a) to connect two AC networks with different frequencies or different frequency control philosophies (back-to-back) or b) to transmit large amounts of power via long distances. For large distances, 
DC transmission lines have lower losses than AC connections. Long in this context meaning more than $\sim 800 \mathrm{~km}$ for overhead lines, and more than $\sim 40 \mathrm{~km}$ for cables. There are two basic converter technologies in use today for HVDC power transmission: the "classical" CSC technology based on thyristors and the more recent self-commutated VSC technology based on IGBTs [11]-[15].

As thyristors are only turn-on devices, the active power flow of CSC systems is controlled by adjusting the turnon (firing) and the extinction time instant (overlap) prior to commutation to another valve. Reactive power is consumed both by the rectifier at the sending, and by the inverter at the receiving end. This has to be compensated for by filters and additional capacitors on the AC sides. In particular under transient conditions, the amount of reactive power consumed varies greatly. The power flow is unidirectional. The reversal of the power flow direction requires a change in polarity of the system, which could be problematic in particular for polymeric cable connections. The technology is quite mature and two $800 \mathrm{kV}$ system have been put in operation recently with power levels of up to $6400 \mathrm{MW}$ ( $800 \mathrm{kV}, 4 \mathrm{kA}$, bipolar) [16]. The losses in one terminal are $\sim 0.7 \%$ [17] at rated current, of which the converter transformer contributes $\sim 50 \%$. The technology is still advancing and further developments which occurred recently are within the thyristor switch itself where voltage and current ratings are continuously increasing, in the application of capacitor commutated conversion which consumes considerably less reactive power [18], [19], or in the reduction of filter size by using continuously tuned ACfilters and active DC-filters [12], [18].

With the advances in power semiconductor devices and the availability of high power transistors (IGBTs [20], [21]), it is also possible to use pulse-width modulation (PWM) or multi-level concepts for HVDC power transmission. The selfcommutated VSC has a stiff DC voltage and large capacitors are used. Due to the use of PWM, only high-frequency harmonics are present and the filters can be considerably smaller. VSC HVDC technology transmits active power and can provide the required amount of reactive power at both, the power sending and the power receiving end. This also allows a reduction of the filter size. However, the losses in one VSC terminal are $\sim 1.6 \%$ [17], [22], of which the converter valves contribute almost $70 \%$. The largest realized VSC based HVDC system is $150 \mathrm{kV}, 400 \mathrm{MW}$ [23] and a $300 \mathrm{kV}, 800 \mathrm{MW}$ system is in the planning phase (BorWin2). The technology is in principle available for higher powers today, limited mainly by the voltage constraints of XLPE DC-cables. In case of a DC-side fault, the diodes connected in parallel to the IGBT modules act as an uncontrolled rectifier, even if the IGBTs are blocked. The short-circuit current is limited only by the AC system [14]. The small DC-side inductance leads to a very high rate of rise of DC current. In addition, the DC-capacitors discharge and add to the fault current [24], [25]. Thus, the DC and AC sides have to be decoupled very quickly to stop the fault current. As the converter is no longer controllable in this fault case (in contrast to CSC HVDC systems), AC circuit breakers are typically used. HVDC circuit breakers could do the same, but are not available today. Due
TABLE I

KEY DIFFERENCES BETWEEN CSC AND VSC BASED HVDC SYSTEMS.

\begin{tabular}{|c|c|c|}
\hline & CSC based & VSC based \\
\hline basic element & thyristor & IGBT \\
\hline $\begin{array}{l}\text { harmonics related } \\
\text { issues }\end{array}$ & $\begin{array}{l}\text { intense low-order } \\
\text { harmonics }\end{array}$ & $\begin{array}{l}\text { weak high- } \\
\text { frequency } \\
\text { components }\end{array}$ \\
\hline $\begin{array}{l}\text { reactive / active } \\
\text { power }\end{array}$ & $\begin{array}{l}\text { consumes large } \\
\text { amount of reactive } \\
\text { power }\end{array}$ & $\begin{array}{l}\text { reactive and active } \\
\text { power can be fully } \\
\text { controlled on both } \\
\text { ends }\end{array}$ \\
\hline losses & $\sim 0.7 \%$ & $\sim 1.6 \%$ \\
\hline $\begin{array}{l}\text { maximum power } \\
\text { rating (bipolar) }\end{array}$ & $\begin{array}{l}\text { up to } 6400 \mathrm{MW} \\
(800 \mathrm{kV}, 4 \mathrm{kA})\end{array}$ & $\begin{array}{l}>\quad 400-800 \mathrm{MW} \\
(300 \mathrm{kV})\end{array}$ \\
\hline $\begin{array}{l}\text { connection to AC- } \\
\text { grid }\end{array}$ & $\begin{array}{l}\text { converter } \\
\text { transformer }\end{array}$ & $\begin{array}{l}\text { series reactor \& } \\
\text { transformer }\end{array}$ \\
\hline $\begin{array}{l}\text { reversal of power } \\
\text { flow direction }\end{array}$ & $\begin{array}{l}\text { change of pole volt- } \\
\text { age }\end{array}$ & $\begin{array}{lr}\text { adjust } & \text { PWM } \\
\text { sequence but } & \text { keep } \\
\text { voltage } & \end{array}$ \\
\hline $\begin{array}{l}\text { control during DC } \\
\text { fault }\end{array}$ & $\begin{array}{l}\text { adjust phase angle } \\
\text { control }\end{array}$ & $\begin{array}{l}\text { control lost (due to } \\
\text { diodes) }\end{array}$ \\
\hline DC side inductors & large & small \\
\hline DC side capacitors & $\begin{array}{l}\text { small (larger with } \\
\text { cables) }\end{array}$ & large \\
\hline $\begin{array}{l}\text { rate of rise of DC } \\
\text { short-circuit current }\end{array}$ & $\begin{array}{l}\text { small and control- } \\
\text { lable }\end{array}$ & large \\
\hline
\end{tabular}

to this vulnerability to DC-side faults, VSC HVDC stations are preferably connected by cables rather than overhead lines as cables are much less sensitive to environmental influences.

The key differences between CSC- and VSC-based HVDC are summarized in Tab. I. With respect to HVDC circuit breakers, the most important ones are the different sizes of capacitances and inductances (and the resulting different rate of rise of the fault current) and the loss of control in VSC HVDC in case of a DC-side fault.

VSC technology is advancing rapidly; new concepts have been proposed and partly demonstrated on a small scale. The aim is to reduce losses to $<1 \%$, to reduce the harmonics content, and even to have the ability to limit and extinguish the current in case of DC side faults [26]-[28].

Most of today's HVDC transmission systems are point-topoint, connecting only two terminals. In principle it is possible to connect a number of $\mathrm{AC}$ nodes with many point-to-point connections in a so called multiple-pair configuration (cf. lefthand side of Fig. 1). However, there are several advantages if the lines would be connected on the DC side, forming a true HVDC network (e.g. like on the right-hand side of Fig. 1). Firstly, the number of converter stations could be reduced as only one converter is needed per AC connection point. Not only does this significantly reduce the costs, but also the losses of the entire transmission system. In addition, each station can transmit (send or receive) power individually and can even change from receiving to sending power without requiring that another station does the opposite. There is more redundancy and power can be transmitted even if one line is lost. In order to ensure the reliable operation of a multi-terminal system it must be possible to decouple faulty lines or stations from the system. In AC systems, circuit breakers that are able to interrupt the full short-circuit current are used. For HVDC, 


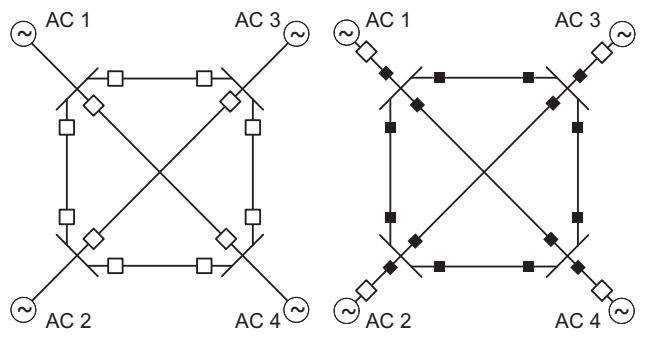

Fig. 1. Example comparison of HVDC network configuration based on point-to-point systems (left) or with the use of HVDC circuit breakers (right). Converter terminal: $\square$, HVDC circuit breaker:

realized circuit breakers have only limited ratings. Compared with AC circuit breakers they are much larger in size and considerably more expensive. Thus, other concepts have been introduced in today's point-to-point systems. Most commonly, DC line faults are interrupted using converter control [29], which only works for CSC, or the circuit breakers on the AC side of the converter stations are operated to de-energize the station and the line [30]. In case of a non-sustained fault, the stations and the line can be re-energized. This operation sequence takes at least a few 100ms [23], [31], [32] up to a few seconds [33], but is well suited for point-to-point connections. De-energizing the entire HVDC networks has also been suggested [24], [34], [35], but it is surely limited to small systems with only three or four terminals [36].

The availability of HVDC circuit breakers is thus a key enabling technology for the reliable and economic operation of multi-terminal HVDC systems. Supporting HVDC circuit breakers by fast action of the terminal controls is undoubtedly of advantage and should be investigated further (in particular also for VSC topologies).

There has been interest in multi-terminal HVDC systems since the 1960's [37] with a clear peak in the 1980's [10], [34], [36], [38]-[40]. Summarizing articles exist [41], [42], but they are all based on CSC HVDC. Only parallel operation in meshed or radial systems are seriously considered, where one terminal is voltage controlled and sets the system voltage level whereas all others are current controlled. More recent publications suggest VSC based multiterminal systems for e.g. offshore-wind farms [2], [43] and urban distribution systems [44], [45]. The challenges with HVDC networks that still have to be addressed before they become reality are numerous [33]: control [46], [47] and protection strategy [24], [31], [48], communication between terminals [39], [49], and current interruption. The question whether it is better to base an HVDC network on CSC or VSC cannot be answered unambiguously. To each technology there are certain advantages and disadvantages. CSC HVDC is well established and has a higher power rating combined with lower losses. But, a fault on the AC-side can lead to commutation failures which results in a collapse of the DC line voltage [9], [36]. A CSCbased network is thus vulnerable to AC-side faults. A VSCbased network in turn is vulnerable to a DC-side fault. As stated above, any DC-side fault will result in a fault current with steeply increasing amplitude. Moreover, CSC requires relatively strong $\mathrm{AC}$ sources and consumes reactive power at
TABLE II

PROS AND CONS FOR BUILDING MULTI-TERMINAL HVDC BASED ON CSC OR VSC.

\begin{tabular}{|c|c|c|}
\hline & Advantage & Disadvantage \\
\hline \multirow[t]{3}{*}{ CSC-based } & $\begin{array}{l}\text { high voltage and } \\
\text { power rating }\end{array}$ & $\begin{array}{l}\text { risk of commutation } \\
\text { failures, collapse of } \\
\text { DC line voltage }\end{array}$ \\
\hline & low losses & $\begin{array}{l}\text { strong AC-side } \\
\text { requirement, } \\
\text { consumes reactive } \\
\text { power }\end{array}$ \\
\hline & $\begin{array}{l}\text { low rate of rise of } \\
\text { short-circuit current }\end{array}$ & $\begin{array}{l}\text { vulnerable to AC- } \\
\text { side faults }\end{array}$ \\
\hline \multirow[t]{3}{*}{ VSC-based } & $\begin{array}{l}\text { stiff voltage on DC } \\
\text { side }\end{array}$ & lower power rating \\
\hline & $\begin{array}{l}\text { power reversal w/o } \\
\text { voltage reversal }\end{array}$ & higher losses \\
\hline & $\begin{array}{l}\text { more suitable for } \\
\text { cables }\end{array}$ & $\begin{array}{l}\text { vulnerable to DC- } \\
\text { side faults }\end{array}$ \\
\hline
\end{tabular}

every terminal location. In contrast, a VSC based network could help to strengthen regions with weak AC systems by its independently controllable active and reactive power. A reversal of power flow direction for one terminal of the network is straightforward for VSC-based systems [15], [46]. In CSC-based systems, the voltage polarity would have to be changed, subsequently affecting the power flow direction at all terminals connected to the common DC voltage line. The arguments for and against building a multi-terminal HVDC system based on CSC or VSC are summarized in Tab. II. The choice of technology is particularly important for the HVDC circuit breakers as it determines the requirements on the HVDC circuit breaker, which would be considerably different. If the basis is VSC, the breaker has to be very fast and has to have very high current interruption capability. As there is no unambiguous decision for any of the two technologies, requirements from both technologies are considered in the following section. It is even possible that the less stringent breaking time criteria will influence multiterminal HVDC system towards CSC based technologies.

\section{HVDC CIRCUIT BREAKERS}

In today's point-to-point HVDC transmission systems, DC interrupters are used for several different switching duties. As neutral bus switch (NBS), neutral bus ground switch (NBGS), metal return transfer breaker (MRTB), ground return transfer breaker (GRTB), high-speed bypass switch (HSBS), for parallel line switching, and isolation switches also exist [50], [51]. Interrupters to break DC short-circuit currents have only been realized in very limited numbers and maximum ratings are $250 \mathrm{kV}, 8 \mathrm{kA}$ [52] or $500 \mathrm{kV}, 4 \mathrm{kA}$ [53], which is not more than 1.6 times the rated nominal current [52]. The breaking time is in the order of $35 \mathrm{~ms}$, but as stated above, for CSC based systems the large inductances limit the rate of rise of fault current and this time is sufficiently fast. However, the components of these breakers are very large and much more costly than AC circuit breakers with comparable current and voltage ratings. In point-to-point HVDC transmission systems the function of DC breakers has thus typically been substituted 
by de-energizing the converter stations, e.g. by acting with the station control or by operating the breakers on the AC side and the opening of isolation switches. In low and medium voltage DC applications, short-circuit current interrupting breakers have been realized based on several different technologies, e.g. switching arcs or solid-state switches.

The difficulties in realizing HVDC circuit breakers can be attributed to the demanding requirements on circuit breakers in DC systems which are quite different to those of AC circuit breakers. One of the major differences is the absence of natural current zero crossings in DC systems. The breakers have to fulfill the following basic requirements (cf. also [54]):

1) Create a current zero crossing to interrupt the current.

2) Dissipate the energy stored in the system inductance.

3) Withstand the voltage response of the network after current interruption.

In particular the first two requirements lead to a very strong interaction between the breaker and the DC system, an attribute which is also very different to AC circuit breakers. In addition to these basic requirements there are, depending on the breaker application, additional secondary requirements:

- In VSC-based systems the HVDC breaker has to be able to interrupt quickly, as was stated above.

- The maximum voltage generated by the breaker must be low enough to comply with the insulation coordination of the DC system. This is particularly important for switching of load currents where the network is at nominal voltage.

As mentioned above, the interest in meshed HVDC systems is almost as old as the HVDC technology itself. In parallel to the interest in HVDC networks, a great amount of research and development was done on HVDC breakers up to the 1980's and has been summarized in 1971 [55], 1983 [56] and partly also in 1991 [57]. Thus, only the basic DC breaker concept is explained here. The details of different variants of this concept can be found in the earlier reviews. After 1985, the interest in HVDC breakers dropped significantly and only in recent years, when the interest in HVDC networks has picked up again, new studies appear. Advances have mainly been made in related technologies that could help to improve the HVDC circuit breaker design. The focus in this paper will be on reviewing the more recent developments, in particular having in mind also the new VSC technology.

\section{A. Basic working principles of HVDC circuit breakers}

The current in a DC circuit can be brought to zero by generating a counter-voltage of similar or larger amplitude than the system voltage. This counter-voltage can be produced by inserting additional resistance or inductance in the current path. The energy of the DC system is dissipated across this device. The larger the counter-voltage, the smaller the time needed to interrupt, but the larger the energy that is dissipated in the device [54]. DC breakers with current limiting and energy dissipating function of an arc are commonly used in low- and medium-voltage applications. Some proposals for high-voltage systems have been made [58], [59], but none of them has proven efficient and successful in real application.

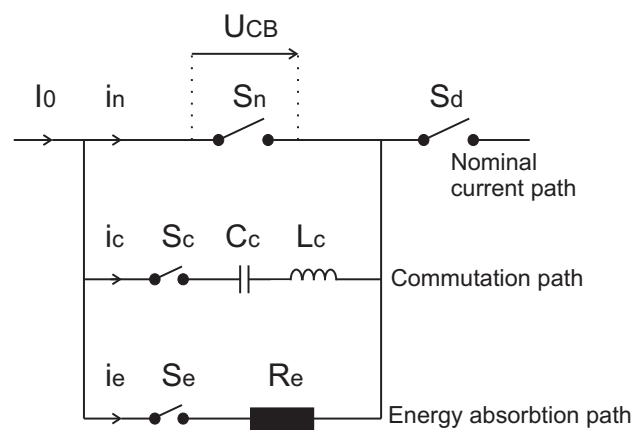

Fig. 2. Basic arrangement of HVDC circuit breaker (adapted from [56]).

An alternative is to have several parallel paths in the breaker and to separate the requirements to different elements. The simplest is one nominal current path and one parallel path with a linear or non-linear resistive element [55]. The nominal current path typically consists of an interrupter with low ohmic losses in closed position, which is so far only possible with movable metallic contacts. Upon opening of these contacts, an arc is established and its arcing voltage is used to commutate the current to the resistive path where the energy of the system is then dissipated. The advantage is that the interrupter in the nominal current path only needs to produce a voltage sufficient for commutation and not for counter-acting on the full system voltage. In addition, the breaker does not have to have a large energy dissipating function, which typically improves its interruption capability. If the commutation path only consists of a linear resistor, the arc voltage of the interrupter still has to be very high. A gradual insertion of resistors or non-linear resistors to limit the required commutation voltage [55] would be better. The commutation process can be eased by adding other elements, such as a capacitor which temporarily takes the current flow [60]. More recent developments make use of actively controllable resistances of solid-state devices (cf. section III-B).

For most of the practically realized HVDC circuit breakers, separate commutation and energy absorbing paths have been used, as sketched in Fig. 2. The commutation path may then be a series resonance consisting of a capacitance $C_{c}$ and inductance $L_{c}$ so that a current oscillation between the nominal and the commutation path can occur at the natural frequency $\omega_{0}^{2}=1 / L_{c} C_{c}$. If the amplitude of the oscillating current $i_{n}$ is larger than the system DC current $I_{0}$, a current zero crossing occurs in the nominal path and the interrupter $S_{n}$ can interrupt the current. Current $I_{0}$ continues to flow, charging the capacitor $C_{c}$ in the commutation path. If the capacitor voltage exceeds a given value, typically chosen to be the voltage capability of the breaker or the insulation coordination of the HVDC system, the energy absorption path acts, causing the system current $I_{0}$ to decrease. If the differential arc resistance $d U / d I$ of the interrupter in the nominal path is negative, a current oscillation between the nominal and the commutation path with increasing amplitude occurs, started by the natural fluctuation in the arc voltage. Fig. 3 shows the currents in the different paths of the breaker and the voltage across it. At time $t_{0}$ a fault occurs and the current $I_{0}$ starts to increase. 

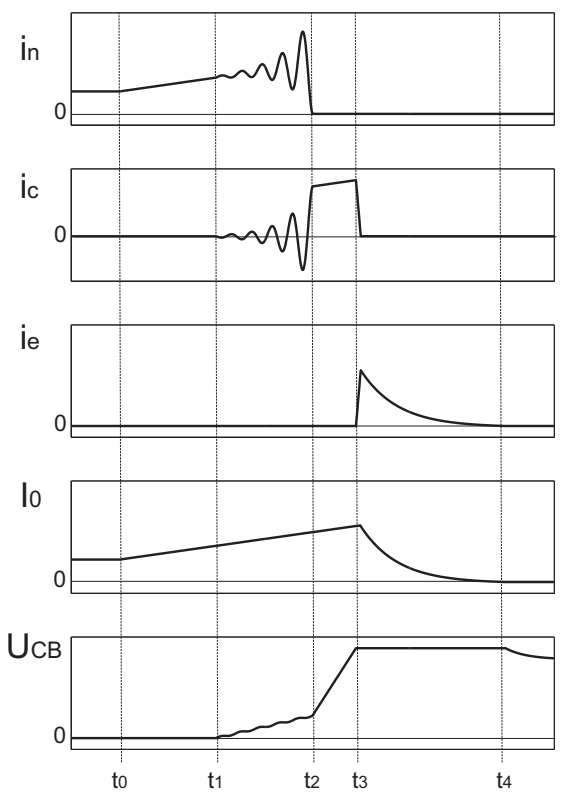

Fig. 3. Basic current and voltage development during interruption (adapted from [56]).

The interrupter contacts of the nominal current path separate at $t_{1}$ and an instable oscillation starts due to the characteristics of the arc voltage. At $t_{2}$ the amplitude of the oscillation is sufficiently large so that $i_{n}$ crosses zero and $S_{n}$ interrupts. The current quickly charges $C_{c}$ until the threshold voltage level of the energy absorbing elements in the third path is reached at time $t_{3}$. This path can consist of energy absorbing linear or non-linear resistors that are inserted with switch $S_{e}$ or be non-linear $\mathrm{ZnO}$ varistors that become partly conductive only above a certain applied voltage and thus don't need an insertion device. The voltage is limited by these elements, current only flows through the energy absorbing path and the current $I_{0}$ of the system ceases.

An alternative to the self-excited growing oscillations with purely passive components in the commutation path is the use of additional active components, like the closing switch $S_{c}$. If the capacitor $C_{c}$ is pre-charged, a current is injected into the nominal path upon closing of $S_{c}$ and a counter-current is induced [61].

Based on this basic working principle, numerous different realizations have been proposed. The total breaker can consist of one single unit [52] or be the series connection of several individual ones with lower voltage rating [61], [62]. The interrupter in the nominal path can be an oil breaker [60], air-blast breaker [62], vacuum interrupter [63]-[65], or an SF6 gas circuit breaker [50], [61], [66]. Breakers where the inductance $L_{c}$ of the commutation path is a separate coil [62] or uses the stray inductance of the path [61] have both been proposed. If the capacitor in the commutation path is precharged, it can be inserted with a spark-gap [67], [68] or a closing switch [52], [69]. The capacitor can be charged with a dedicated charging unit with isolation switch or directly from the line [52], [69]. The energy absorption can be realized by linear or non-linear resistors [55] or non-linear $\mathrm{ZnO}$ surge arrestors [61], [62]. From the combination of these possible configurations, numerous breakers have been proposed and a few have been realized. However, the maximum ratings are quite limited, as already stated above, especially with respect to interruption times.

\section{B. More recent activities and related fields of technology}

1) Adaptions of the basic principle: The basic principle of HVDC circuit breakers, as shown in Fig. 2 and described in the previous section, has been continuously optimized. Special focus is on making better use of the most costly components, the capacitors and varistors. Methods have been derived to calculate and select the optimum value of the capacitor $C_{c}$ and to extend the current interruption range. In a configuration with a passive commutation path, a set of criteria is derived based on the characteristic surge impedance $\sqrt{L_{c} / C_{c}}$ and the characteristic frequency $\omega_{0}$ [70]. The criteria are chosen to minimize the interruption time and to enhance the interruption performance. If the configuration of active current injection with pre-charged capacitor is chosen, a large $C_{c} / L_{c}$ ratio is of advantage as it leads to larger injected current with the same energy stored in the capacitor [71]. Also here, a set of criteria combining the $C_{c} / L_{c}$-ratio with the natural frequency $\omega_{0}$ is chosen to maximize the interruption performance. The current oscillations in the nominal and commutation path of passive arrangements grow if the arc characteristic is negative. A fast growing oscillation at a high natural frequency leads to faster current interruption. The AC circuit breakers that are typically used as elements in the nominal path are by no means optimized for this. Thus, dedicated investigations studying the arc characteristics under different conditions have been performed [50], [72], [73] and it was even tried to optimize the breaker [66]. Nonetheless, as the classical configuration with only passive elements is probably the most economic and most reliable one, further investigation of the arc behavior under different conditions to optimize the breaker is surely needed. A dedicated arcing chamber for optimal excitation of the oscillations could become interesting if an HVDC network becomes reality and the number of breakers needed grows. This chamber does not necessarily have to have a high interruption capability as another breaker, dedicated for current interruption, could be placed in series in the nominal current path. In addition to the passive variant, the growing oscillations can also be actively excited. In [74] it is proposed to add a power transistor in parallel to the interrupter in the nominal current path that is pulsed at the natural frequency $\omega_{0}$ between conducting and an appropriate high voltage level. This pulsing excites the current oscillation, preferably faster and more reliably than the instable arc condition can.

The development and optimization of such breakers requires sophisticated testing (cf. also later section) and there have been attempts to substitute some of the tests with simulations. The interaction of the breaker with a real network is modeled with transient simulation programs [75], [76], where the arc is represented by a black-box model [77] with some free parameters that are fitted to experiments. So far, the focus of these 
simulations was more on the behavior of the network rather than optimizing the breaker itself. As long as the programs are run with black-box models, these models have to be verified and calibrated by basic arc measurements. An optimization of the breaker with these type of simulations must always be accompanied by experiments. Progress has been made in simulating AC switching arcs of gas circuit breakers [78] and vacuum interrupters [79] using multi-physics simulations that need less, or even no fitting parameters at all. These type of simulations should be used to optimize the arcing conditions for use in HVDC circuit breakers in addition to black-box models. Equally important as the oscillation excitation is the interruption capability of the interrupter. In contrast to $\mathrm{AC}$ circuit breakers, the current slope $d I / d t$ before current zero and the rate of rise of the transient recovery voltage $d U / d t$ (RRTRV) across $S_{n}$ after current interruption are determined by the breaker itself and not by the network. The current slope before interruption depends on the oscillation frequency and amplitude (growth) and may vary over a large range. The switching arc gap is stressed by the voltage of the capacitor, charged by $I_{0}$, in the parallel path. A detailed understanding of the current interruption process and the interruption limits of the breaker with different arcing conditions is necessary and has to be gained by experiments and simulations. Vacuum circuit breakers have been proposed as building elements for HVDC circuit breakers [63], [64] as they combine a high interruption performance (large $d I / d t$ with large $d U / d t$ ) with small breaking times $(<5 \mathrm{~ms})$. Unfortunately, the maximum voltage withstand of vacuum interrupters is limited to medium voltage levels $\left(U_{n} \leq 36 \mathrm{kV}\right)$ and only a series arrangement could reach high voltage levels. This is mechanically very demanding and needs to be studied in further detail.

Depending on the selected HVDC technology the focus of future research in optimizing existing schemes is placed on one of the directions mentioned above. Especially the requirement of fast interruption will be challenging to meet with a classical configuration.

Another application of a similar configuration is for the magnetic coils of the planned fusion experiment ITER, which are planned to be operated with 70kA DC current. This leads to a stored magnetic energy of 40GJ. If a fault in the superconducting coils is detected, this current needs to be interrupted and the energy dissipated within $\sim 11$ s [80], [81]. The interrupter scheme is composed of a bypass switch in parallel with an interrupter and a counter current injection from a pre-charged capacitor. The current is commutated to a discharge resistor where the energy is dissipated. The nominal current and energy rating are considerably higher than for HVDC circuit breakers, but the rated voltage is only $17.5 \mathrm{kV}$ and the interruption time is $500 \mathrm{~ms}$.

2) Combined optimization of Topology, Control, and Breaker: Most of the research on HVDC, multi-terminal schemes, and HVDC circuit breakers focuses only on a particular individual aspect. Sometimes the breaker is assumed to be known and the network control is designed around it. Other times, the requirements for HVDC circuit breakers are set by the system control activities and the breaker has to be designed accordingly. No combined attempts to optimize the system as a whole are reported. It would be thinkable to adjust the control scheme to ease the requirements for circuit breakers. Adding additional inductance to the DC side in VSC-based networks would limit the rate of rise of the short-circuit current and simplify the hard breaking time requirement, but would lead to slower control in normal operation. If high impedance grounding is used, the short-circuit current during DC-line to ground faults is limited. Focusing on only one aspect is most probably not optimum, only a combined optimization could lead to the globally best solution. Another example for combined optimization is for VSC-schemes using multi-level converters [15], [82]. Voltage levels at a fraction of the total DC line voltage occur inside the valve and in principle it would be possible to interrupt at these levels. The respective DC breakers would have a lower voltage rating, but the topology of the valves needs to be redesigned to incorporate DC breakers. Only a combined effort of valve and breaker design would lead to a satisfying result.

3) Standardization: A new multiterminal HVDC system will be built using components from more than one manufacturer. Standards and norms for multiterminal HVDC should be set [23]. This is particularly important for circuit breakers and their interfaces to the network and protection system.

4) Solid-State DC breakers: Also discussed are pure semiconductor switches [35], [83]-[85], not only for HVDC, but also for low and medium voltage $\mathrm{DC}$ and $\mathrm{AC}$. The clear advantage is that the switching time can be as low as a few $\mu$ s, compared to a few (ten) ms of a mechanical switch with separating metal contacts. The main drawbacks are costs and the fact that the resistance in conducting mode is in the order of a few $\mathrm{m} \Omega$ and thus considerably higher compared to a few $\mu \Omega$ for a mechanical switch [86]. The full forward conduction losses of the solid state devices are $\sim 0.1-0.4 \%$ [17], [87] of the transmitted power. The application of semiconductor switches was thus typically limited to applications where a high power quality is of crucial importance and the minimum breaking time is absolutely needed. As stated above, the rate of rise of short-circuit current in VSC-based HVDC networks is very high. So far, no other HVDC circuit breaker concept is available with breaking times in the order of $1 \mathrm{~ms}$ and thus, a solid-state switch is the only feasible solution today. A single semiconductor device is not able to withstand the full voltage and current rating [88], but a series and parallel arrangement of several switches is possible to achieve HVDC circuit breaker ratings.

Research and development in the solid-state switching devices, the semiconductor material itself, and in concepts where the high on-state losses of solid state switches can be avoided, so-called hybrid concepts, have to be intensified. This is discussed in the next two sections.

5) Semiconductor devices: The performance of semiconductor devices continues to increase constantly, not only in blocking voltage rating, but also in maximum current rating for a single chip [89]. In future, HVDC valves and potentially also HVDC circuit breakers can be realized with fewer components which improves the performance and decreases the losses. Today, all devices are based on silicon and an even bigger step ahead would be the change of semiconductor material to 
a wide band-gap material. $\mathrm{SiC}, \mathrm{GaN}$ and diamond have been discussed and are intensively investigated [90], [91]. Wide band gap materials have a higher breakdown field strengths $E_{c}$ compared to $\mathrm{Si}(\mathrm{Si}: 0.3, \mathrm{SiC}$ : $1.2-2.4, \mathrm{GaN}$ : 3.3, and diamond: $5.6 \mathrm{MV} / \mathrm{cm}$ ). For a comparable voltage capability the chip could be significantly thinner which decreases the losses of the device. For example, a SiC-pin-diode was fabricated with $4.2 \mathrm{kV}$ breakdown voltage with 5 times lower conduction losses than Si-based diodes with comparable ratings [92]. Still, no competitive wide band-gap devices are commercially available, but research and development is pursued intensively in this region and great advances can be expected in the next years or decades. Any progress in this area will influence HVDC technology, including the possibility of designing solid-state HVDC circuit breakers, significantly.

6) Hybrid circuit breakers: It was already stated in the last section that semiconductors have high conduction losses and are thus not optimal as in-line switches or circuit breakers. Hybrid switching schemes are therefore proposed. Here, the nominal current path is contains a mechanical breaker with low resistive metal contacts that are separated quickly, causing the current to commutate to a parallel path with the semiconductor switch. When the current is transferred and the dielectric strength between the metallic contacts has recovered, the semiconductor switch is operated. Schemes are proposed for AC circuit breakers [86], [87], [93], AC capacitor switches [94], Fault Current Limiting Units [95] and also for DC circuit breakers [85], [96].

Other hybrid concepts, where gas and vacuum circuit breakers are connected in series, exist as well. Here speed is not the primary aim, but the combination of the high current and high frequency interruption capability of vacuum circuit breakers together with the high voltage withstand capability of gas circuit breakers. These schemes are continuously under discussion for both HVDC breakers [68] and AC circuit breakers [97]. These type of hybrid concepts are of principal interest, but the interaction of different devices is often complex and makes a detailed understanding of the working principle, and careful consideration when coupling, necessary.

7) Fast Switches: One of the key devices for hybrid DC circuit breakers using solid-state switches is a very fast mechanical switch with low conduction losses in the nominal current path. These fast switches have to operate in $<1 \mathrm{~ms}$ and to build-up sufficient arc voltage to cause the current to commutate to the interruption path. Concepts for fast switches based on electromagnetically driven contacts in air [86], [98] or vacuum circuit breakers [73], [99] have been developed. In low voltage networks, these switches also have a current limiting function and ratings for circuit breakers have reached $4 \mathrm{kA} / 1.5 \mathrm{kV}$ with breaking time $\sim 300 \mu \mathrm{s}$ [100]. The requirements for fast switches in hybrid breakers operating in $<1 \mathrm{~ms}$ are independent of AC or DC. For high-voltage systems, new concepts or series arrangements of many switches would be necessary and research should be carried out in this area.

8) Fault Current Limiters: Many of the concepts to fulfill the basic requirements of an HVDC circuit breaker, as discussed above, are also applicable for fault current limiters (FCL) in both AC and DC systems. The task of fault current limiters is, as the name implies, to limit the maximum overcurrent in a power system when a fault occurs. The FCL thus needs to increase the impedance of the systems, either selftriggered or externally triggered. The FCL has to be effective before the peak current is reached, typically $1-3 \mathrm{~ms}$ in $50 \mathrm{~Hz} \mathrm{AC}$ systems. In addition, the FCL has to handle the large amounts of energy dissipated during the limitation. In addition, some FCL also interrupt the current. If they cannot do so, a load break switch has to be placed in series to interrupt the limited current. Some review articles have been published [101], [102] and the details of FCL will not be repeated here. Amongst the different operation principles are solid state fault current limiters (SSFCL) [84], [103] and hybrid concepts using fast mechanical switches [104]. Both concepts have been discussed above, but have not been realized for high voltages so far. Medium-voltage fuses [105], [106] work as self-triggered FCL with interruption capability, but they are one-shot devices which have to be replaced manually and are widely available only up to $10-20 \mathrm{kV}$. Superconducting fault current limiters (SCFCL) [107], [108] of resistive type make use of the intrinsic physical property that superconductors lose their zero resistance above a critical current density. These types of fault current limiters have low conduction losses in nominal operation, are fast and resettable but require extensive cooling of the material to reach the superconducting state. Resistive SCFCL could be used as fast acting commutation switches placed in the nominal current path, but disconnectors have to be placed in series as the SCFCL has no voltage withstand capability.

Most fault current limiters have been designed for distribution voltage levels $(<36 \mathrm{kV})$. For the higher voltages on the subtransmission and transmission level, only limiting reactors and resonance links with in-line capacitors have been realized [102]. Research and development for high voltage FCL is ongoing [107], [109] and any progress in this area is also of benefit for HVDC circuit breaker activities. Even unconventional concepts as a series connection of SCFCL with puffer breaker in $\mathrm{LN}_{2}$ [110] are investigated.

9) Testing: So far only the circuit breaker itself has been addressed. The breaker or its individual components have to be tested for functionality during development. Direct testing methods are not possible for the high power ratings, thus, synthetic testing methods have to be used [50], [111]. In contrast to $\mathrm{AC}$ circuit breaker testing, the breaker interacts strongly with the network and thus, real energy levels have to be used to stress the breaker appropriately. This is difficult, costly and leads to strong heating of e.g. the energy dissipating elements. Special test circuits have been used, mainly for component testing [112]. With power-hardware in the loop methods individual component tests could be accelerated and simplified. In this method, only the component of the system which is under investigation is a real physical device. All other components and their interaction with the test object are simulated with a real-time simulator [108], [113]-[115]. For an HVDC circuit breaker, this could mean that the interaction with the network and the energy dissipation could be simulated. The corresponding current through the breaker is calculated and driven by a flexible current source. 


\section{Summary of Future Research Needs}

Throughout the previous sections of the text, several technological areas where research and development is needed in order to improve or enable HVDC circuit breakers were identified and discussed. These areas are summarized in the list below:

- Optimization of existing basic HVDC circuit breaker scheme by optimizing the size of elements like capacitors, inductors, varistors, or charging units. Main goal is a reduction in size, interruption time, and costs.

- Optimization of switching arcs with respect to growth of oscillation and capability to interrupt by detailed investigation of arc characteristics under many different conditions for gas and vacuum circuit breakers. Derivation and verification of the parameters in mathematical arc models.

- Multi-physics simulation of HVDC arcs for high current (growing current oscillation) and interruption phase.

- Extension of medium voltage circuit breakers to higher voltage levels. Either by improving the technology, by series connection, or by applying breakers across medium voltage levels in multi-level converter topologies.

- Fast mechanical switches or disconnectors with high recovery voltage withstand and low on-state-losses. Ideally, these switches have sufficient arcing voltage for fast commutation. Use of such a switch in a hybrid circuit breaker.

- Pure semiconductor switch with minimal on-state-losses. Use of new wide band-gap power semiconductor devices, e.g. $\mathrm{SiC}$ or $\mathrm{GaN}$.

- Fault current limiters for medium and high voltage.

- Combined optimization of the whole system: breakercontrol-protection.

- New testing methods for HVDC circuit breakers or its individual components. Due to the strong breaker-network interaction, power hardware in the loop techniques would be advantageous.

- Standards and norms for multiterminal HVDC.

\section{ACKNOWLEDGMENT}

Thanks to Michael Walter for plotting the graphs. Thanks to Michael Walter, Göran Andersson, Markus Bujotzek, and Emil Iggland for careful proof-reading of the manuscript and their helpful suggestions for improvements.

\section{REFERENCES}

[1] N. Kirby, L. Xu, M. Luckett, and W. Siepmann, "HVDC transmission for large offshore wind farms," Power Engineering Journal, vol. 16, pp. $135-141$, Jun. 2002.

[2] W. Lu and B. Ooi, "Optimal acquisition and aggregation of offshore wind power by multiterminal voltage-source HVDC," IEEE Trans. Power Del., vol. 18, pp. 201-206, Jan. 2003.

[3] C. Meyer, M. Hoeing, A. Peterson, and R. W. DeDoncker, "Control and design of DC grids for offshore wind farms," IEEE Trans. Ind. Appl., vol. 43, pp. 1475-1482, Nov.-Dec. 2007.

[4] DLR, "Trans-mediterranean interconnection for concentrating solar power," German Aerospace Center, Institute of Technical Thermodynamics, Section Systems Analysis and Technology Assessment, Tech. Rep., 2006, available: http://www.dlr.de/tt/trans-csp.
[5] V. Billon, J. Taisne, V. Arcidiacono, and F. Mazzoldi, "The Corsican tapping: from design to commissioning tests of the third terminal of the Sardinia-Corsica-Italy HVDC,' IEEE Trans. Power Del., vol. 4, pp. 794-799, Jan. 1989.

[6] D. McCallum, G. Moreau, J. Primeau, M. Bahrman, B. Ekehov, and D. Soulier, "Multiterminal integration of the Nicolet Converter Station into the Quebec-New England Phase II HVDC transmission system," in Proc. of CIGRE 35th International Conf. on Large High Voltage Electric Systems, Paris, France, no. vol.1, Aug.-Sep. 1994, pp. 14 $103 / 1-9$.

[7] A. Greenwood, K. Kanngiessner, V. Lesclae, T. Margaard, and W. Schultz, "Circuit breakers for meshed multiterminal HVDC systems Part I: Introduction DC side substation switching under normal and fault conditions," Electra, no. 163, pp. 98-122, Dec. 1995.

[8] - "Circuit breakers for meshed multiterminal HVDC systems. Part II: Switching of transmission lines in meshed MTDC systems," Electra, no. 164, pp. 62-82, Feb. 1996.

[9] L. Bergstrom, L.-E. Juhlin, G. Liss, and S. Svensson, "Simulator Study of Multiterminal HVDC System Performance," IEEE Trans. Power App. Syst., vol. PAS-97, pp. 2057 -2066, Nov. 1978.

[10] K. Kanngiesser, H. Ring, and T. Wess, "Simulator study on line fault clearing by DC circuit breakers in a meshed MTDC system," in International Conf. on AC and DC Power Transmission, London, UK, Sept. 1991, pp. $102-107$.

[11] J. Arrillaga, High Voltage Direct Current Transmission. The Institution of Electrical Engineers, London, United Kingdom, 1998.

[12] J. Arrillaga, Y. H. Liu, and N. R. Watson, Flexible Power Transmission: The HVDC Option. John Wiley \& Sons Ltd., England, 2007.

[13] M. Bahrman and B. Johnson, "The ABCs of HVDC transmission technologies," IEEE Power and Energy Magazine, vol. 5, pp. 32 -44, Mar.-Apr. 2007.

[14] N. Flourentzou, V. Agelidis, and G. Demetriades, "VSC-Based HVDC Power Transmission Systems: An Overview," IEEE Trans. Power Electron., vol. 24, pp. 592 -602, Mar. 2009.

[15] B. Andersen, L. Xu, P. Horton, and P. Cartwright, "Topologies for VSC transmission," Power Engineering Journal, vol. 16, p. 142, Jun. 2002.

[16] Q. Yuan and L. Yun, "Xiangjiaba-Shanghai highest power of UHVDC ready for implementation," in IEEE PES Transmission and Distribution Conf. and Exposition, Apr. 2008, pp. 1-5.

[17] H. Pang, G. Tang, and Z. He, "Evaluation of losses in VSC-HVDC transmission system," in IEEE Power and Energy Society General Meeting - Conversion and Delivery of Electrical Energy in the 21st Century, Pittsburgh, PA, USA, Jul. 2008, pp. $1-6$.

[18] L. Carlsson, “"Classical” HVDC: Still continuing to evolve," Modern Power Systems, vol. 22, pp. 19-21, Jun. 2002.

[19] A. Gole and M. Meisingset, "Capacitor commutated converters for long-cable HVDC transmission," Power Engineering Journal, vol. 16, pp. $129-134$, Jun. 2002.

[20] S. Linder, Power Semiconductors. EPFL Press, Switzerland, 2006.

[21] K. Sheng, B. Williams, and S. Finney, "A review of IGBT models," IEEE Trans. Power Electron., vol. 15, pp. 1250 -1266, Nov. 2000.

[22] G. Daelemans, K. Srivastava, M. Reza, S. Cole, and R. Belmans, "Minimization of steady-state losses in meshed networks using VSC HVDC," in IEEE PES General Meeting, Jul. 2009, pp. 1-5.

[23] E. Koldby and M. Hyttinen, "Challenges on the Road to an Offshore HVDC Grid," in Nordic Wind Power Conf., Denmark, Sept. 2009.

[24] L. Tang and B.-T. Ooi, "Protection of VSC-multi-terminal HVDC against DC faults," in IEEE 33rd Annual Power Electronics Specialists Conf., vol. 2, 2002, pp. 719-724.

[25] S. Allebrod, R. Hamerski, and R. Marquardt, "New transformerless, scalable Modular Multilevel Converters for HVDC-transmission," in IEEE Power Electronics Specialists Conf., Jun. 2008, pp. 174-179.

[26] H. Huang, "Multilevel Voltage-Source Converters for HVDC and FACTS Application," in CIGRE SC B4 Bergen Colloquium, 2009, p. paper 401.

[27] B. Jacobson, P. Kalsson, G. Asplund, L. Harnefors, and T. Jonsson, "VSC-HVDC Transmission with Cascaded Two-Level Converters," in CIGRE session, 2010, pp. B4-110.

[28] D. Trainer, C. Davidson, C. Oates, N. MacLeod, D. Critchley, and R. Crookes, "A New Hybrid Voltage-Source Converter for HVDC Power Transmission," in CIGRE session, 2010, pp. B4-111.

[29] A. Li, Z. Cai, Q. Sun, X. Li, D. Ren, and Z. Yang, "Study on the dynamic performance characteristics of HVDC control and protections for the HVDC line fault," in IEEE Power Energy Society General Meeting, Jul. 2009, pp. 1 -5.

[30] S. Sekine, "DC Line Fault Protection in Multiterminal HVDC PowerSystems," Electrical Engineering in Japan, vol. 92, pp. 73-80, 1972. 
[31] M. Takasaki, N. Gibo, K. Takenaka, T. Hayashi, H. Konishi, S. Tanaka, and H. Ito, "Control and protection scheme of HVDC system with self-commutated converter in system fault conditions," Electrical Engineering in Japan, vol. 132, pp. 6-18, Jul. 2000.

[32] N. Gibo, K. Takenaka, S. Verma, S. Sugimoto, and S. Ogawa, "Protection scheme of voltage sourced converters based HVDC system under DC fault," in IEEE PES Transmission and Distribution Conf. and Exhibition: Asia Pacific, vol. 2, Oct. 2002, pp. 1320-1325.

[33] V. Lescale, A. Kumar, L.-E. Juhlin, H. Bjorklund, and K. Nyberg, "Challenges with multi-terminal UHVDC transmissions," in Joint International Conf. on Power System Technology and IEEE Power India Conf. (POWERCON), Piscataway, NJ, USA, Oct. 2008.

[34] W. Long, J. Reeve, J. McNichol, M. Holland, J. Taisne, and J. LeMay, "Application aspects of multiterminal DC power transmission," IEEE Trans. Power Del., vol. 5, pp. 2084 -2098, Oct. 1990.

[35] L. Tang and B.-T. Ooi, "Locating and isolating DC faults in multiterminal DC systems," IEEE Trans. Power Del., vol. 22, pp. 18771884, Jul. 2007.

[36] W. Long, J. Reeve, J. Mcnichol, R. Harrison, and D. Fletcher, "Consideration for implementing multiterminal dc systems," IEEE Trans. Power App. Syst., vol. PAS-104, pp. 2521 -2530, Sept. 1985.

[37] U. Lamm, E. Uhlmann, and P. Danfors, "Some aspects of tapping of H.V.D.C. transmission systems," Direct Current, vol. 8, pp. 124-129, May 1963.

[38] J. Bowles, "Multiterminal HVDC Transmission Systems Incorporating Diode Rectifier Stations," IEEE Trans. Power App. Syst., vol. PAS-100, pp. $1674-1678$, Apr. 1981.

[39] T. Sakurai, K. Goto, S. Irokawa, K. Imai, and T. Sakai, "A New Control Method for Multiterminal HVDC Transmission Without Fast Communications Systems," IEEE Trans. Power App. Syst., vol. PAS102, pp. 1140-1150, May 1983.

[40] F. Nozari, C. Grund, and R. Hauth, "Current Order Coordination in Multiterminal DC Systems," IEEE Trans. Power App. Syst., vol. PAS100 , pp. $4628-4635$, Nov. 1981.

[41] J. Reeve and J. Carr, "Review of techniques for multi-terminal HVDC systems," in International Conf. on High Voltage DC and/or AC Power Transmission, 1973, pp. 269-73.

[42] J. Reeve, "Multi-Terminal HVDC Power-Systems," IEEE Trans. Power App. Syst., vol. 99, pp. 729-737, Mar./Apr. 1980.

[43] D. Jovcic, "Interconnecting offshore wind farms using multiterminal VSC-based HVDC," in IEEE Power Engineering Society General Meeting, 2006, p. 7 pp.

[44] H. Jiang and A. Ekstrom, "Multiterminal HVDC systems in urban areas of large cities," IEEE Trans. Power Del., vol. 13, pp. 1278 -1284, Oct. 1998.

[45] R. Billinton, M. Fotuhi-Firuzabad, and S. Faried, "Reliability evaluation of hybrid multiterminal HVDC subtransmission systems," IEE Proceedings - Generation, Transmission and Distribution, vol. 149, pp. $571-577$, Sept. 2002.

[46] H. Chen, C. Wang, F. Zhang, and W. Pan, "Control Strategy Research of VSC Based Multiterminal HVDC System," in Power Systems Conf. and Exposition, PSCE, Atlanta, USA, Nov. 2006, pp. 1986 -1990.

[47] G. Li, M. Yin, M. Zhou, and C. Zhao, "Decoupling Control for Multiterminal VSC-HVDC Based Wind Farm Interconnection," in IEEE Power Engineering Society General Meeting, Jun. 2007, pp. 1-6.

[48] H. Liu, Z. Xu, and Y. Huang, "Study of protection strategy for VSC based HVDC system," in IEEE PES Transmission and Distribution Conf. and Exposition, Sept. 2003, pp. 49-54.

[49] M. Ishikawa, S. Horiuchi, S. Irokawa, K. Imai, S. Hirose, and K. Sekiya, "Simulator Study of Multiterminal HVDC Transmission System without Fast Communication," IEEE Trans. Power Del., vol. 1, pp. $218-227$, Jul. 1986.

[50] D. Andersson and A. Henriksson, "Passive and Active DC Breakers in the Three Gorges-Changzhou HVDC Project," Proc. of the Int. Conf. Power Systems, ICPS, pp. 391-395, 2001.

[51] A. Jain, S. Chakravorty, L. Rao, and M. Prasad, "Design requirements for the DC breaker/switches for Rihand-Delhi HVDC project," in Power Systems for the Year 2000 and Beyond. Proceedings of the Sixth National Power Systems Conf., Jun. 1990, pp. 197-200.

[52] S. Tokuyama, K. Arimatsu, Y. Yoshioka, and Y. Kato, "Development and Interrupting Tests on 250KV 8KA HVDC Circuit Breaker," IEEE Trans. Power App. Syst., vol. PAS-104, pp. 2452-2459, Sep. 1985.

[53] B. Pauli, G. Mauthe, E. Ruoss, G. Ecklin, and J. Porter, "Development of a high current HVDC circuit breaker with fast fault clearing capability," IEEE Trans. Power Del., vol. 3, pp. 2072-2080, Oct. 1988.

[54] W. Pucher, "Fundamentals of HVDC Interruption," Electra, no. 5, pp. 24-38, Jun. 1968.
[55] W. Pucher, P. Joss, B. Koetzold, T. Lee, and V. Zajic, "HVDC switching devices and arrangements," Electra, no. 18, pp. 9-65, Jul. 1971.

[56] J. Vithayathil, "HVDC Breaker and its Application," in Proc. of the Int. Symp. on HVDC Technology "Sharing the Brazilian Experience", 1983, pp. Paper 2-4.

[57] K. Nakanishi, Switching Phenomena in High-Voltage Circuit Breakers. Marcel Dekker, Inc., 1991, ch. 3.5 High-Voltage Direct-Current Circuit Breakers, pp. 163-175.

[58] H. Schulze, "Zur Verwirklichung der Last- und Leistungsschalter für hochgespannten Gleichstrom," ETZ-A, vol. 85, no. 21, p. 702, 1964

[59] E. Marx, "Erzeugung sehr hoher Lichtbogenspannungen fuer Gleichstrom-Hochspannungsschalter," ETZ-A, vol. 86, no. 21, pp. 701702, 1965.

[60] H. Haertel, D. Kind, E. Marx, K. Moellenhoff, and J. Salge, "Entwicklung und Erprobung eines Versuchsschalters für die HochspannungsGleichstrom-Übertragung," ETZ-A, vol. 89, no. 18, pp. 421-423, 1968

[61] A. Lee, P. Slade, K. Yoon, and J. Porter, "The Development of a HVDC SF6 Breaker," IEEE Trans. Power App. Syst., vol. 104, pp. 2721-2729, Oct. 1985.

[62] B. Bachmann, G. Mauthe, E. Ruoss, H. Lips, J. Porter, and J. Vithayathil, "Development of a 500kV airblast HVDC circuit breaker," IEEE Trans. Power App. Syst., vol. 104, pp. 2460-2466, Sept. 1985.

[63] A. Greenwood, W. Kracht, and P. Barkan, "HVDC Vacuum Circuit Breakers," IEEE Trans. Power App. Syst., vol. 91, pp. 1575-1588, 1972.

[64] J. Anderson and J. Carroll, "Applicability of a Vacuum Interrupter as the Basic Switch Element in HVDC Breakers," IEEE Trans. Power App. Syst., vol. PAS-97, pp. 1893-1900, Sept. 1978.

[65] W. Premerlani, "Forced Commutation Performance of Vaccum Switches for HVDC Breaker Application," IEEE Trans. Power App. Syst., vol. PAS-101, pp. 2721 -2727, Aug. 1982.

[66] H. Nakao, Y. Nakagoshi, M. Hatano, T. Koshizuka, S. Nishiwaki, A. Kobayashi, T. Murao, and S. Yanabu, "DC current interruption in HVDC SF6 gas MRTB by means of self-excited oscillation superimposition," IEEE Trans. Power Del., vol. 16, pp. 687-693, Oct. 2001.

[67] M. Sakai, Y. Kato, S. Tokuyama, H. Sugawara, and K. Arimatsu, "Development and Field Application of Metallic Return Protecting Breaker for HVDC Transmission," IEEE Trans. Power App. Syst., vol. PAS-100, pp. 4860-4868, Dec. 1981.

[68] T. Senda, T. Tamagawa, K. Higuchi, and T. Horiuchi, "Development of HVDC Circuit Breaker Based on Hybrid Interruption Scheme," IEEE Trans. Power App. Syst., vol. PAS-103, pp. 545 -552, Mar. 1984.

[69] S. Tokuyama, K. Hirasawa, and Y. Yoshioka, "Simulations on Interruption of Circuit Breaker in HVDC System with Two Parallel Transmission Lines," IEEE Trans. Power Del., vol. 2, pp. 772 -778, Jul. 1987.

[70] H. Ito, T. Moriyama, K. Kamei, S. Hamano, E. Nitta, N. Takeji, K. Yamaji, and M. Hatano, "Apparatus for gas circuit breaker with reactor and capacitor connected in series and method for setting its circuit parameter," European Patent EP0740320, 1996.

[71] U. Astrom, L. Liljestrand, V. Lescale, and M. Backman, "A DC Current Breaker," PCT Patent Application WO 2009/149749, 2009.

[72] H. Ito, S. Hamano, K. Ibuki, K. Yoshinaga, T. Hasegawa, K. Yamaji, and H. Irokawa, "Instability of DC arc in SF6 circuit breaker," IEEE Trans. Power Del., vol. 12, pp. 1508-1513, Oct. 1997.

[73] H. Odaka, M. Yamada, R. Sakuma, C. Ding, E. Kaneko, and S. Yanabu, "DC interruption characteristic of vacuum circuit breaker," Electrical Engineering in Japan, vol. 161, pp. 17-25, Oct. 2007.

[74] G. Asplund, V. Lescale, and C. E. Soelver, "Direct-current breaker for high power," Patent Application EP0660352(B1), 1995.

[75] H. Darwish, M. Izzularab, and N. Elkalashy, "Real-time testing of hvdc circuit breakers part 1: bench test development," in International Conf. on Electrical, Electronic and Computer Engineering, ICEEC, Sep. 2004, pp. 765-769.

[76] — "Real-time testing of hvdc circuit breakers part II: real-time cases," in International Conf. on Electrical, Electronic and Computer Engineering, ICEEC, Sep. 2004, pp. 770-773.

[77] WG 13.01, "Applications of black box modelling to circuit breakers," Electra, no. 149, pp. 40-71, Aug. 1993.

[78] A. Iordanidis and C. Franck, "Self-consistent radiation-based simulation of electric arcs: II. Application to gas circuit breakers," Journal of Physics D: Applied Physics, vol. 41, p. 135206, Jul. 2008.

[79] T. Delachaux, O. Fritz, D. Gentsch, E. Schade, and D. Shmelev, "Simulation of a High Current Vacuum Arc in a Transverse Magnetic Field," IEEE Trans. Plasma Sci., vol. 37, pp. 1386 -1392, Aug. 2009.

[80] T. Bonicelli, A. De Lorenzi, D. Hrabal, R. Piovan, E. Sachs, E. Salpietro, and S. Shaw, "The European development of a full scale switching 
unit for the ITER switching and discharging networks," Fusion Engineering and Design, vol. 75-9, pp. 193-200, Nov. 2005.

[81] F. Milani, "Upgrade of the RFX energy transfer system for a reliable 35kV, 50kA DC-current interruption," Fusion Engineering and Design, vol. 84, pp. 1300-1304, Jun. 2009.

[82] Y. Liu, J. Arrillaga, and N. Watson, "Addition of four-quadrant power controllability to multi-level VSC HVDC transmission," IET Generation, Transmission Distribution, vol. 1, pp. 872 -878, Nov. 2007.

[83] S. Schroder, C. Meyer, and R. De Doncker, "Solid-state circuit breakers and current-limiting devices for medium-voltage systems," in IEEE International Power Electronics Congress, 2002, pp. 91-95.

[84] C. Meyer, S. Schroder, and K. De Doncker, "Solid-state circuit breakers and current limiters for medium-voltage systems having distributed power systems," IEEE Trans. Power Electron., vol. 19, pp. 1333-1340, Sept. 2004.

[85] G. De Langer, A. Chol, and N. Ijumba, "Application of high-power semiconductor technology in DC traction circuit-breakers," in IEEE Power Engineering Society Inaugural Conf. and Exposition in Africa, Jul. 2006, pp. 494-8.

[86] A. Atmadji and J. Sloot, "Hybrid switching: A review of current literature," in International Conf. on Energy and Management and Power Delivery, EMPD, 1998, pp. 683-688.

[87] C. Meyer and R. De Doncker, "Solid-state circuit breaker based on active thyristor topologies," IEEE Trans. Power Electron., vol. 21, pp. 450-458, Mar. 2006

[88] E. Carroll, "Power electronics for very high power applications," in Seventh International Conf. on Power Electronics and Variable Speed Drives, no. 456, 1998, pp. 218-223.

[89] S. Linder, "High-power semiconductor devices. Review and comparative assessment," Russian Electrical Engineering, vol. 78, pp. 509-14, October 2007.

[90] M. Trivedi and K. Shenai, "Performance evaluation of high-power wide band-gap semiconductor rectifiers," J. of Appl. Phys., vol. 85, pp. 68896897, May 1999

[91] A. Elasser and T. Chow, "Silicon carbide benefits and advantages for power electronics circuits and systems," Proceedings of the IEEE, vol. 90, pp. 969-986, Jun. 2002.

[92] K. Fujihira, S. Tamura, T. Kimoto, and H. Matsunami, "Low-loss, highvoltage $6 \mathrm{H}-\mathrm{SiC}$ epitaxial p-i-n diode," IEEE Trans. Electron Devices, vol. 49 , pp. $150-154$, Jan. 2002

[93] C. Meyer, M. Kowal, and R. De Doncker, "Circuit breaker concepts for future high-power DC-applications," in Conf. Record of the 2005 IEEE Industry Applications Conf. Fortieth IAS Annual Meeting, no. 2 , 2005 2005, pp. 860-6.

[94] M. Backman, M. Dahlgren, S. Halen, O. Jepsson, and L. Liljestrand, "A diode based transient free capacitor switch," in 19th International Conf. on Electricity Distribution, CIRED, 2007, p. paper 0665.

[95] J. Dupraz and G. Montillet, "New network concepts using electronic hybrid circuit breakers," in IEEE/PES Transmission and Distribution Conf. \& Exposition, Apr. 2008, pp. 1-8.

[96] S. Hasan, M. Atout, and S. Al-Dhalan, "Protection of the modified HVDC converters using an ultra fast hybrid circuit breaker," in European Conf. on Power Electronics and Applications, 1999, pp. 1-9.

[97] R. P. P. Smeets, V. Kertesz, D. Dufournet, D. Penache, and M. Schlaug, "Interaction of a vacuum arc with an SF6 arc in a hybrid circuit breaker during high-current interruption," IEEE Trans. Plasma Sci., vol. 35, pp. 933-938, Aug. 2007.

[98] W. Holaus and K. Frohlich, "Ultra-fast switches- a new element for medium voltage fault current limiting switchgear," in IEEE Power Engineering Society Winter Meeting, vol. 1, 2002, pp. 299-304.

[99] T. Genji, O. Nakamura, M. Isozaki, M. Yamada, T. Morita, and M. Kaneda, "400V Class High-Speed Current Limiting Circuit-Breaker for Electric Power System," IEEE Trans. Power Del., vol. 9, pp. 14281435, Jul. 1994.

[100] J.-M. Meyer and A. Rufer, "A DC hybrid circuit breaker with ultra-fast contact opening and integrated gate-commutated thyristors (IGCTs)," IEEE Trans. Power Del., vol. 21, pp. 646 - 651, Apr. 2006.

[101] M. Steurer and K. Fröhlich, "Current Limiters - State of the Art," in Fourth Workshop \& Conf. on EHV Technology, Indian Institute of Science, Bangalore, India, 1998.

[102] WG A3.10, "Fault Current Limiters in Electrical Medium and High Voltage Systems," Cigre Brochure 239, 2003.

[103] R. Smith, P. Slade, M. Sarkozi, E. Stacey, J. Bonk, and H. Mehta, "Solid-state distribution current limiter and circuit breaker: application requirements and control strategies," IEEE Trans. Power Del., vol. 8 , pp. $1155-1164$, Jul. 1993.
[104] M. Steurer, K. Fröhlich, and W. Holaus, "A novel hybrid currentlimiting circuit breaker for medium voltage: principle and test results," IEEE Trans. Power Del., vol. 18, pp. 460-467, Apr. 2003.

[105] A. Wright and P. Newbery, Electric Fuses - 3rd edition. The Institution of Electrical Engineers, London, UK, 2004.

[106] M. Saqib and A. Stokes, "Arc Behavior and Confinement in a HighVoltage, High Breaking Capacity Fuse Filler," IEEE Trans. Power Del., vol. 25, pp. 212-220, Jan. 2010.

[107] M. Noe and M. Steurer, "High-temperature superconductor fault current limiters: concepts, applications, and development status," Supercond. Sci. Technol, vol. 20, pp. R15-R29, Mar. 2007.

[108] C. Schacherer, J. Langston, M. Steurer, and M. Noe, "Power Hardwarein-the-Loop Testing of a YBCO Coated Conductor Fault Current Limiting Module," IEEE Trans. Appl. Supercond., vol. 19, pp. 18011805, Jun. 2009

[109] S. Orpe and N.-K. Nair, "State of art of fault current limiters and their impact on overcurrent protection," in IEEE Power \& Energy Society General Meeting, Jul. 2009

[110] Y. Morishita, T. Koyama, I. Yamaguchi, S. Okabe, G. Ueta, and S. Yanabu, "Development of dc-current-limiting circuit-breaker with superconducting fault current limiter," Proc. XVII International Conf. on Gas Discharges and their Applications , pp. 97-100, 2008.

[111] B. Sheng, "A synthetic test circuit for current switching tests of HVDC circuit breakers," in IEEE/PES Transmission and Distribution Conf. and Exposition, Apr. 2008, pp. 1-4.

[112] H. Brumshagen, "Ueber die Pruefung von Schalteinrichtungen fuer die Hochspannungs-Gleichstrom-Uebertragung," Ph.D. dissertation, Technische Universitaet zu Braunschweig, 1975.

[113] P. McLaren, R. Kuffel, R. Wierckx, J. Giesbrecht, and L. Arendt, "A real time digital simulator for testing relays," IEEE Trans. Power Del., vol. 7, pp. $207-213$, Jan. 1992.

[114] P. Terwiesch, T. Keller, and E. Scheiben, "Rail vehicle control system integration testing using digital hardware-in-the-loop simulation," IEEE Trans. Control Syst. Technol., vol. 7, pp. 352 -362, May 1999.

[115] M. Steurer, C. S. Edrington, M. Sloderbeck, W. Ren, and J. Langston, "A Megawatt-Scale Power Hardware-in-the-Loop Simulation Setup for Motor Drives," IEEE Trans. Ind. Electron., vol. 57, pp. $1254-1260$, Apr. 2010

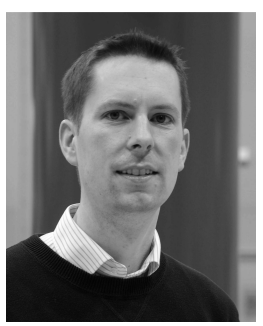

Christian M. Franck (M '04) received a diploma and Ph.D. in physics in 1999 and 2003, respectively. He worked at the Swiss corporate research center of $\mathrm{ABB}$ as a scientist and group leader for gas circuit breakers and high voltage systems. He is currently assistant professor for high voltage technology at the Swiss Federal Institute of Technology (ETH) in Zurich, Switzerland. 